\title{
Sickness absence and disability pension among injured working-aged pedestrians - a population-based Swedish register study
}

\author{
Linnea Kjeldgård ${ }^{1 *}$, Helena Stigson 1,2,3 ${ }^{1}$, Maria Klingegård ${ }^{3}$, Kristina Alexanderson ${ }^{1}$ and Emilie Friberg ${ }^{1}$
}

\begin{abstract}
Background: The knowledge is scarce about sickness absence (SA) and disability pension (DP) among pedestrians injured in a traffic-related accident, including falls. Thus, the aim was to explore the frequencies of types of accidents and injuries and their association with SA and DP among working-aged individuals.

Methods: A nationwide register-based study, including all individuals aged 16-64 and living in Sweden, who in 2010 had in- or specialized outpatient healthcare after a new traffic-related accident as a pedestrian. Information on age, sex, sociodemographics, SA, DP, type of accident, injury type, and injured body region was used. Frequencies of pedestrians with no SA or DP, with ongoing SA or full-time DP already at the time of the accident, and with a new SA spell $>14$ days in connection to the accident were analyzed. Crude and adjusted odds ratios (ORs) with 95\% confidence intervals (Cls) for new SA were estimated by logistic regression.
\end{abstract}

Results: In total, 5576 pedestrians received healthcare due to a traffic-related accident (of which $75 \%$ were falls, with half of the falls related to snow and ice). At the time of the accident, $7.5 \%$ were already on SA and $10.8 \%$ on full-time DP, while 20\% started a new SA spell. The most common types of injuries were fractures (45\%) and external injuries (30\%). The body region most frequently injured was the lower leg, ankle, foot, and other (in total 26\%). Older individuals had a higher OR for new SA compared with younger (OR 1.91; 95\% Cl 1.44-2.53, for ages: 45-54 vs. 25-34). The injury type with the highest OR for new SA, compared with the reference group external injuries, was fractures (9.58; 7.39-12.43). The injured body region with the highest OR for new SA, compared with the reference group head, face, and neck, was lower leg, ankle, foot, and other (4.52; 2.78-7.36).

Conclusions: In this explorative nationwide study of the working-aged pedestrians injured in traffic-related accidents including falls, one fifth started a new SA spell >14 days. Fractures, internal injuries, collisions with motor vehicle, and falls related to snow and ice had the strongest associations with new SA.

Keywords: Sick leave, Disability pension, Pedestrians, Fall accidents, Traffic injury, Population-based, Cross-sectional, Insurance medicine, Real-world data

\footnotetext{
*Correspondence: linnea.kjeldgard@ki.se

${ }^{1}$ Division of Insurance Medicine, Department of Clinical Neuroscience,

Karolinska Institutet, SE-171 77 Stockholm, Sweden

Full list of author information is available at the end of the article
}

\begin{abstract}
Background
Active transportation such as walking provides an opportunity for individuals to incorporate physical activity into daily life. Therefore, active transport is encouraged by different stakeholders [1-3] and in line with the UN's global goals on sustainability $[4,5]$. However, active transport is not without risks. Globally,
\end{abstract} original author(s) and the source, provide a link to the Creative Commons licence, and indicate if changes were made. The images or other third party material in this article are included in the article's Creative Commons licence, unless indicated otherwise in a credit line to the material. If material is not included in the article's Creative Commons licence and your intended use is not permitted by statutory regulation or exceeds the permitted use, you will need to obtain permission directly from the copyright holder. To view a copy of this licence, visit http://creativecommons.org/licenses/by/4.0/. The Creative Commons Public Domain Dedication waiver (http://creativeco mmons.org/publicdomain/zero/1.0/) applies to the data made available in this article, unless otherwise stated in a credit line to the data. 
pedestrians represent about a fifth off all fatalities within the road transport system $[5,6]$. The European Commission estimates that for every person killed in road traffic crashes, an additional five suffer serious injuries [7]. In the EU, pedestrians represent the road user group with the highest proportion of accidents resulting in hospital admission [8].

Little is known about the consequences of these injuries among working-aged pedestrians in terms of sickness absence (SA) and disability pension (DP). Long-term SA or DP among injured individuals are consequences of road traffic accidents that impact the individual as well as their family, colleagues, employer, insurer, and society [9, 10]. These consequences are a major economic and political factor to consider, e.g., when establishing new policies [11].

Nevertheless, the current definition of traffic injuries [12], only includes pedestrians struck by vehicles. Several studies have indicated that if falls outdoors in public spaces were also included, the numbers of injured would be up to 35 times higher [2]. Thus, in order to avoid underestimation of injuries among pedestrians, accidents from falls sustained in the road transport system should also be included.

To get a broader understanding of SA and DP among pedestrians injured in traffic-related accidents, including falls within the road transport system, the aim of this study was to explore SA and DP among all individuals of working ages who were injured as a pedestrian, both in general and by sociodemographics, type of accident, type of injury, and injured body region.

\section{Methods}

A population-based register study was conducted. The study population included all pedestrians aged 16-64 years, living in Sweden 31 December 2009, who in 2010 received in- or specialized outpatient healthcare due to an injury sustained in a new traffic-related accident, including falls.

Data from five nationwide registers from the following three authorities were used and linked at the individual level, using the unique personal identity number assigned to all residents in Sweden [13]:

- From Statistics Sweden, the Longitudinal Integration Database for Health Insurance and Labour Market Studies (LISA) was used to identify the source population of all 16-64 years old individuals living in Sweden 31 December 2009 (N=5 973 769) and information on sociodemographics (sex, age, educational level, country of birth, type of living area, and marital status).
- From the National Board of Health and Welfare, the in- and specialized outpatient registers were used to identify the study population as well as for medical information related to the injury. The Cause of Death Register was used to identify those who had died within the first 30 days after the accident.

- From the Swedish Social Insurance Agency, the register, Micro-data for Analyses of the Social Insurance (MiDAS) was used for information on dates and extent of SA and DP.

In the in- and specialized outpatient healthcare registers, the diagnoses (one main and all secondary diagnoses) and external causes of morbidity are both recorded according to the International Statistical Classification of Diseases and Related Health Problems; ICD-10 [14]. Individuals who received in- or specialized outpatient healthcare in 2010 due to an injury caused by a falls, a collision with another person, or a collision with a transport vehicle were identified by the ICD-10 codes for external causes of morbidity: "Pedestrian injured in transport accident" (V01-V09), "fall accidents, street and highway" (W00.4, W01.4, W02.4, W03.4, W04.4, W05.4, W10.4, W15.4, W17.4, W18.4, W19.4), and "striking against or bumped into by another person, street and highway" (W51.4).

These individuals $(n=6299)$ will hereafter be referred to as the 'pedestrians' and the injuries as 'traffic-related injuries'. The date of the accident, denoted as $T_{0}$, refers the date of the in- or specialized outpatient healthcare visit/hospitalization as the actual date of their accident/ fall is not included in the registers.

To include only new accidents, the pedestrians who had received in- or specialized outpatient healthcare for another traffic-related accident during the three years prior to their date of the accident $\left(\mathrm{T}_{0}\right)$ were excluded $(n=498)$, leaving 5801 pedestrians. Furthermore, those 225 who did not have an injury diagnosis as a main or secondary diagnosis (ICD10: S00-T88 "Injury, poisoning and certain other consequences of external causes") were excluded, leaving a study population of 5576 pedestrians. Those who died in immediate connection to the crash, i.e., who did not receive in- or specialized outpatient healthcare, were not included. Whereas the six pedestrians who died within 30 days of the accident were included.

Based on type of accident, the pedestrians were categorized into the following six groups: collision with pedestrian/bicyclist (V01, W03.4, W04.4, W51.4); collision with motor vehicle (V02-V06, V09.0, V09.2); unspecified (V09.1, V09.3, V09.9, W19.4); fall - snow/ice, street and highway (W00.4); fall - slipping, tripping, and stumbling, street and highway (W01.4) (reference group); and 
fall - other, street and highway (W02.4, W05.4, W10.4, W15.4, W17.4, W18.4) (including: involving ice-skates, skis, roller-skates or skateboards, involving wheelchair, on and from stairs and steps, from cliff, from one level to another, and on same level). Type of healthcare was also categorized into three groups as: only specialized outpatient healthcare (reference group); inpatient healthcare $<3$ days; and inpatient healthcare $\geq 3$ days (the median duration of the hospital stay among those hospitalized was 3 days).

According to the patient registers, some pedestrians had up to three different healthcare visits registered on $\mathrm{T}_{0}$. Every visit had a main diagnosis and could also have a number of additional secondary diagnoses. The majority had only one injury diagnosis. For categorization purposes, for those with several injury diagnoses, we selected one injury diagnosis per pedestrian, in the following way: The main injury diagnosis was selected over secondary injury diagnoses, the diagnoses for inpatient healthcare over outpatient healthcare, and S00-S99 over T00-T88.

A modified version of the Barell matrix [15] was used to classify the ICD-10 codes into categories of type of injury and injured body region. Similar categorizations were used in recent studies on injuries among car occupants and bicyclists [16-19]. Type of injury was categorized into the following six groups: fracture; dislocation; sprains and strains; internal (brain, spinal cord, and other internal organs); external (open wounds, contusions, and superficial injuries) (reference group); and "other and unspecified".

The injured body region was categorized into ten groups: head, face, and neck (reference group); vertebral column and spinal cord; torso; shoulder and upper arm; forearm and elbow; wrist, hand, and other; hip, upper leg, and thigh; knee; lower leg, ankle, foot, and other; and "other and unspecified".

The sociodemographic covariates were categorized as: sex (women; men (reference group)), age group (1624; 25-34 (reference group); 35-44; 45-54; 55-64 years), level of education (elementary school ( $\leq 9$ years including missing); high school (9-12 years); university/college (>12 years) (reference group)), country of birth (Sweden (reference group); not Sweden), type of living area (big cities (reference group); medium-sized cities; small cities/ villages), marital status (married (reference group); not married). Reference groups were chosen based on size of the groups and expected proportions with new SA, with larger groups or groups expected to have lower proportions of new SA being used as the reference.

All individuals living in Sweden, $\geq 16$ years old, and with income from work, unemployment, or parentalleave benefits can apply for SA benefits from the Social
Insurance Agency if having a disease or injury that leads to reduced work capacity [20]. The first day of a SA spell is an unreimbursed qualifying day (more days for selfemployed). A physician's certificate is required after day 7. For employees, day 2-14 are reimbursed by the employer [20]. For others, e.g., unemployed, the Social Insurance Agency administrates the benefits from the second day of SA, thus information on shorter SA spells was available for these individuals. In order not to introduce a bias, only information on SA spells $>14$ days was used. All individuals aged 19-64 can be granted DP if disease or injury leads to long-term or permanent work incapacity. Both SA and DP can be granted for full- or part-time $(100,75,50,25 \%)$ of ordinary work hours. That is, someone on part-time DP can at the same time have part-time SA. For the calculation of mean and median net days of SA (for SA spells $>14$ days), gross SA days were summed to whole days (e.g., two days of $50 \%$ parttime SA was counted as 1 net day).

Pedestrians were categorized into four groups regarding SA/DP at $\mathrm{T}_{0}$ as follows: already ongoing full-time DP; already ongoing SA; new SA; and no new SA. To be defined as already having ongoing SA, the SA spell had to have started at least five days before $\mathrm{T}_{0}$ and still be ongoing at $\mathrm{T}_{0}$. When assessing SA, any SA spells $>14$ days, regardless of extent (full-time, part-time) were included. Considering DP, only full-time DP was categorized as already being on DP. As it is possible to be on part-time DP and receive a new SA, the group "no new SA" includes not only pedestrians without any SA or DP but also pedestrians with ongoing part-time DP but no new SA spell $>14$ days. Being on part-time DP at the date of the accident was instead included as a covariate in the analyses. The pedestrians might not have received in- or specialized outpatient healthcare on the actual date of the accident, e.g., they could have sought primary healthcare first, and they might not have applied for SA benefits the first day, due to e.g., holidays, thus a window of starting days for $\mathrm{SA}$ in relation to $\mathrm{T}_{0}$ was allowed. A new $\mathrm{SA}$ spell in relation to the accident was defined as an SA spell that had started between 4 days before and 4 days after $\mathrm{T}_{0}$. The choice of the timespan of \pm 4 days was based on distribution of start dates of SA in relation to the date of the in- or specialized outpatient healthcare visit/hospitalization $\left(\mathrm{T}_{0}\right)$, with significantly more SA spells starting on $\mathrm{T}_{0}$, but also during the days immediately before or after.

\section{Statistical analyses}

The pedestrian's sex, age, level of education, country of birth, type of living area, marital status, part-time DP, type of accident, type and duration of healthcare, type of injury, and injured body region were shown by SA and DP status at $\mathrm{T}_{0}$, using descriptive statistics. 
Odds ratios (ORs) and 95\% confidence intervals (CIs) for new SA were estimated by logistic regression. In these analyses, pedestrians with already ongoing SA or full-time DP were excluded $(n=1022)$ as those pedestrians not were at risk of a new SA spell, leaving 4554 pedestrians. First, the ORs for new SA by the sociodemographic factors were calculated, in univariate models (crude), adjusted for sex (model 1), adjested for age (model 2), then, mutually adjusted (model 3 ), as well as adjusted by the accident type and injury characteristics (model 4). Then, the ORs for new SA for the characteristics of the accident were estimated, first adjusted for sociodemographic factors (model 1, 2, and 3 ) and then for type of accident, type of injury, and injured body region (model 4 and 5), and in model 6,7 and 8 both the sociodemographic factors and the accident and injury characteristics were taken into consideration. These analyses were also stratified by sex. Moreover, sensitivity analyses excluding pedestrians on part-time DP were performed.

The statistical analyses were performed using SPSS (version 26) and STATA (version 14).

\section{Results}

In total, 5576 pedestrians of working ages received in- or specialized outpatient healthcare due to injury caused by a new traffic-related accident in 2010 (Table 1). Among the injured pedestrians, a higher proportion were in the older age groups and a somewhat higher proportion were women (56.2\%). A majority were born in Sweden (84.2\%),

Table 1 Characteristics of all pedestrians aged 16-64 with a road traffic injury (including falls) in 2010 regarding sociodemographics and part-time disability pension (DP), by sickness absence (SA) and DP status at accident date ( $\left.T_{0}\right)$

\begin{tabular}{|c|c|c|c|c|c|c|c|c|c|c|}
\hline & \multicolumn{2}{|l|}{ All } & \multicolumn{2}{|c|}{ No new SA } & \multicolumn{2}{|c|}{ New SA } & \multicolumn{2}{|c|}{ Ongoing SA } & \multicolumn{2}{|c|}{$\begin{array}{l}\text { Ongoing full- } \\
\text { time DP }\end{array}$} \\
\hline & $\mathbf{n}$ & $\%^{a}$ & $\mathbf{n}$ & $\%^{b}$ & $\mathbf{N}$ & $\%^{\mathbf{b}}$ & $\mathrm{n}$ & $\%^{b}$ & $n$ & $\%^{\mathbf{b}}$ \\
\hline Total & 5576 & 100 & 3424 & 61.4 & 1130 & 20.3 & 420 & 7.5 & 602 & 10.8 \\
\hline \multicolumn{11}{|l|}{ Sex } \\
\hline Women & 3134 & 56.2 & 1800 & 57.4 & 733 & 23.4 & 257 & 8.2 & 344 & 11.0 \\
\hline Men & 2442 & 43.8 & 1624 & 66.5 & 397 & 16.3 & 163 & 6.7 & 258 & 10.6 \\
\hline \multicolumn{11}{|l|}{ Age group, years } \\
\hline $16-24$ & 1076 & 19.3 & 950 & 88.3 & 70 & 6.5 & 33 & 3.1 & 23 & 2.1 \\
\hline $25-34$ & 701 & 12.6 & 501 & 71.5 & 116 & 16.5 & 51 & 7.3 & 33 & 4.7 \\
\hline $35-44$ & 923 & 16.6 & 577 & 62.5 & 207 & 22.4 & 81 & 8.8 & 58 & 6.3 \\
\hline $45-54$ & 1232 & 22.1 & 623 & 50.6 & 325 & 26.4 & 107 & 8.7 & 177 & 14.4 \\
\hline $55-64$ & 1644 & 29.5 & 773 & 47.0 & 412 & 25.1 & 148 & 9.0 & 311 & 18.9 \\
\hline \multicolumn{11}{|l|}{ Level of education } \\
\hline Elementary school & 1444 & 25.9 & 950 & 65.8 & 170 & 11.8 & 77 & 5.3 & 247 & 17.1 \\
\hline High school & 2656 & 47.6 & 1503 & 56.6 & 640 & 24.1 & 232 & 8.7 & 281 & 10.6 \\
\hline University/college & 1476 & 26.5 & 971 & 65.8 & 320 & 21.7 & 111 & 7.5 & 74 & 5.0 \\
\hline \multicolumn{11}{|l|}{ Country of birth } \\
\hline Sweden & 4695 & 84.2 & 2889 & 61.5 & 964 & 20.5 & 365 & 7.8 & 477 & 10.2 \\
\hline Not Sweden & 881 & 15.8 & 535 & 60.7 & 166 & 18.8 & 55 & 6.2 & 125 & 14.2 \\
\hline \multicolumn{11}{|l|}{ Type of living area } \\
\hline Big cities & 1786 & 32.0 & 1127 & 63.1 & 331 & 18.5 & 154 & 8.6 & 174 & 9.7 \\
\hline Medium-sized cities & 2213 & 39.7 & 1358 & 61.4 & 457 & 20.7 & 163 & 7.4 & 235 & 10.6 \\
\hline Small cities/villages & 1577 & 28.3 & 939 & 59.5 & 342 & 21.7 & 103 & 6.5 & 193 & 12.2 \\
\hline \multicolumn{11}{|l|}{ Marital status } \\
\hline Married & 1952 & 35.0 & 1115 & 57.1 & 527 & 27.0 & 150 & 7.7 & 160 & 8.2 \\
\hline Not married & 3624 & 65.0 & 2309 & 63.7 & 603 & 16.6 & 270 & 7.5 & 442 & 12.2 \\
\hline \multicolumn{11}{|l|}{ Part-time DP at $\mathrm{T}_{0}$} \\
\hline No & 5334 & 95.7 & 3299 & 61.8 & 1057 & 19.8 & 376 & 7.0 & 602 & 11.3 \\
\hline Yes & 242 & 4.3 & 125 & 51.7 & 73 & 30.2 & 44 & 18.2 & 0 & 0.0 \\
\hline
\end{tabular}

a Column percent

b Row percent 
were not married (65.0\%), and had high school or college/university education (74.1\%).

Most of the pedestrians (61.4\%) did not have an ongoing SA spell $>14$ days or full-time DP at $\mathrm{T}_{0}$, nor began a new SA spell at $\mathrm{T}_{0}$. While $20.3 \%$ had a new SA spell, $7.5 \%$ had ongoing SA and $10.8 \%$ had ongoing full-time DP. Having a new SA spell was more common among those who were older, women, or married, and among those with ongoing part-time DP. Among those with new SA, the median number of net days of the new SA spells was 50 days, and the mean was 77 days. Most of the individuals with a new SA spell had full-time SA (88.9\%). Among all pedestrians, $4.3 \%$ had ongoing part-time DP.
The two most common accident types were pedestrian falls related to snow and ice (36.3\%) and falls related to slipping, tripping, and stumbling (28.0\%) (Table 2). All types of falls accounted for $75.4 \%$ of the accidents. Accidents including collision with pedestrian, bicycle or motor vehicle stood for $16.5 \%$ of all accidents. Most pedestrians, 4552 (81.6\%) had only specialized outpatient healthcare. Among those with inpatient healthcare $\geq 3$ days, the proportion with a new SA spell was high (45.5\%) when compared with those with inpatient healthcare $<3$ days $(29.0 \%)$, or compared with those with only specialized outpatient healthcare (16.0\%).

Table 2 Accident and injury characteristics of all pedestrians aged 16-64 with a road traffic injury (including falls) in 2010, by sickness absence (SA) and disability pension (DP) status at accident date $\left(\mathrm{T}_{0}\right)$

\begin{tabular}{|c|c|c|c|c|c|c|c|c|c|c|}
\hline & \multicolumn{2}{|l|}{ All } & \multicolumn{2}{|c|}{ No new SA } & \multicolumn{2}{|c|}{ New SA } & \multicolumn{2}{|c|}{ Ongoing SA } & \multicolumn{2}{|c|}{$\begin{array}{l}\text { Ongoing full- } \\
\text { time DP }\end{array}$} \\
\hline & $\mathrm{n}$ & $\%^{\mathrm{a}}$ & $\mathrm{n}$ & $\%^{\mathbf{b}}$ & $\mathrm{n}$ & $\%^{\mathrm{b}}$ & $\mathrm{n}$ & $\%^{\mathbf{b}}$ & $n$ & $\%^{\mathrm{b}}$ \\
\hline Total & 5576 & 100 & 3424 & 61.4 & 1130 & 20.3 & 420 & 7.5 & 602 & 10.8 \\
\hline \multicolumn{11}{|l|}{ Type of accident } \\
\hline Collision with pedestrian/bicyclist & 245 & 4.4 & 165 & 67.3 & 33 & 13.5 & 23 & 9.4 & 24 & 9.8 \\
\hline Collision with motor vehicle & 676 & 12.1 & 426 & 63.0 & 123 & 18.2 & 52 & 7.7 & 75 & 11.1 \\
\hline Unspecified & 452 & 8.1 & 327 & 72.3 & 50 & 11.1 & 29 & 6.4 & 46 & 10.2 \\
\hline Fall - snow/ice & 2022 & 36.3 & 1104 & 54.6 & 562 & 27.8 & 160 & 7.9 & 196 & 9.7 \\
\hline Fall - slipping, tripping, and stumbling & 1563 & 28.0 & 968 & 61.9 & 272 & 17.4 & 109 & 7.0 & 214 & 13.7 \\
\hline Fall - other & 618 & 11.1 & 434 & 70.2 & 90 & 14.6 & 47 & 7.6 & 47 & 7.6 \\
\hline \multicolumn{11}{|l|}{ Healthcare } \\
\hline Only specialized outpatient care & 4552 & 81.6 & 3046 & 66.9 & 728 & 16.0 & 351 & 7.7 & 427 & 9.4 \\
\hline Inpatient care $<3$ day & 386 & 6.9 & 195 & 50.5 & 112 & 29.0 & 28 & 7.3 & 51 & 13.2 \\
\hline Inpatient care $\geq 3$ days & 638 & 11.4 & 183 & 28.7 & 290 & 45.5 & 41 & 6.4 & 124 & 19.4 \\
\hline \multicolumn{11}{|l|}{ Type of injury } \\
\hline Fracture & 2505 & 44.9 & 1083 & 43.2 & 892 & 35.6 & 253 & 10.1 & 277 & 11.1 \\
\hline Dislocation & 182 & 3.3 & 120 & 65.9 & 33 & 18.1 & 14 & 7.7 & 15 & 8.2 \\
\hline Sprains and strains & 849 & 15.2 & 645 & 76.0 & 76 & 9.0 & 68 & 8.0 & 60 & 7.1 \\
\hline Internal & 316 & 5.7 & 216 & 68.4 & 34 & 10.8 & 20 & 6.3 & 46 & 14.6 \\
\hline External & 1644 & 29.5 & 1294 & 78.7 & 89 & 5.4 & 63 & 3.8 & 198 & 12.0 \\
\hline Other and unspecified & 80 & 1.4 & 66 & 82.5 & $<8$ & 7.5 & $<8$ & 2.5 & $<8$ & 7.5 \\
\hline \multicolumn{11}{|l|}{ Body region } \\
\hline Head, face, and neck & 893 & 16.0 & 671 & 75.1 & 50 & 5.6 & 35 & 3.9 & 137 & 15.3 \\
\hline Vertebral column and spinal cord & 74 & 1.3 & 40 & 54.1 & 17 & 23.0 & 11 & 14.9 & 6 & 8.1 \\
\hline Torso & 285 & 5.1 & 193 & 67.7 & 37 & 13.0 & 18 & 6.3 & 37 & 13.0 \\
\hline Shoulder and upper arm & 535 & 9.6 & 282 & 52.7 & 118 & 22.1 & 75 & 14.0 & 60 & 11.2 \\
\hline Forearm and elbow & 402 & 7.2 & 211 & 52.5 & 121 & 30.1 & 30 & 7.5 & 40 & 10.0 \\
\hline Wrist, hand, and other & 1175 & 21.1 & 709 & 60.3 & 282 & 24.0 & 81 & 6.9 & 103 & 8.8 \\
\hline Hip, upper leg, and thigh & 187 & 3.4 & 104 & 55.6 & 39 & 20.9 & 16 & 8.6 & 28 & 15.0 \\
\hline Knee & 536 & 9.6 & 345 & 64.4 & 72 & 13.4 & 51 & 9.5 & 68 & 12.7 \\
\hline Lower leg, ankle, foot, and other & 1448 & 26.0 & 834 & 57.6 & 390 & 26.9 & 102 & 7.0 & 122 & 8.4 \\
\hline Other and unspecified & 41 & 0.7 & 35 & 85.4 & $<8$ & 9.8 & $<8$ & 2.4 & $<8$ & 2.4 \\
\hline
\end{tabular}

a Column percent

b Row percent 
Fractures and external injuries were the most common injury types, accounting for 44.9 and $29.5 \%$ of all injuries, respectively. Beginning a new SA spell was most common among pedestrians with a fracture (35.6\%) and least common for external injuries (5.4\%).

The most commonly injured body regions were upper and lower extremities with most injuries in the subgroup lower leg, ankle, foot, and other (26.0\%) followed by the wrist, hand, and other (21.1\%). Head, face, and neck stood for $16.0 \%$ of all injuries. New SA was most common among pedestrians with injuries to the forearm and elbow (30.1\%).

In the analysis of ORs for new SA, only those 4554 pedestrians at risk for new SA were included. The adjusted OR for a new SA among women compared with men was 1.25 (95\% CI 1.06-1.49) (Table 3). The OR for new SA was higher among older pedestrians compared to younger. When stratifying by sex and after adjusting for potential confounders, results remained similar among both women and men (data not shown).

Regarding the accident and injury characteristics, having had inpatient healthcare $\geq 3$ days was associated with new SA both in the crude analysis OR 6.63 (95\% CI 5.42-8.11) and after adjusting for sociodemographic factors and for accident- and injury-related factors (Model 8: OR 3.65 (95\% CI 2.82-4.73)) (Table 4). Since the type of healthcare was correlated to the type of injury, we in the final model, model 7 , did not include healthcare to limit the risk of over adjusting. The type of accident was, in the final model (model 7) associated

Table 3 Odds ratios (ORs) and 95\% confidence intervals (Cls) for new sickness absence (SA) following a road traffic injury (including falls), by sociodemographics, among the 4554 injured pedestrians without already ongoing SA or full-time disability pension

\begin{tabular}{|c|c|c|c|c|c|c|}
\hline All at risk of SA & $\mathrm{N}(\% \mathrm{SA})$ & $\begin{array}{l}\text { Crude } \\
\text { OR }(95 \% \mathrm{Cl})\end{array}$ & $\begin{array}{l}\text { Model } 1 \\
\text { OR }(95 \% \mathrm{Cl})\end{array}$ & $\begin{array}{l}\text { Model } 2 \\
\text { OR }(95 \% \mathrm{Cl})\end{array}$ & $\begin{array}{l}\text { Model } 3 \\
\text { OR }(95 \% \mathrm{Cl})\end{array}$ & $\begin{array}{l}\text { Model } 4 \\
\text { OR }(95 \% \mathrm{Cl})\end{array}$ \\
\hline \multicolumn{7}{|l|}{ Sex } \\
\hline Women & $2533(28.9)$ & $1.67(1.45-1.91)$ & & $1.38(1.19-1.59)$ & $1.39(1.20-1.61)$ & $1.25(1.06-1.49)$ \\
\hline Men & $2021(19.6)$ & ref. & & ref. & ref. & ref. \\
\hline \multicolumn{7}{|l|}{ Age group, years } \\
\hline $16-24$ & $1020(6.9)$ & $0.32(0.23-0.44)$ & $0.32(0.23-0.43)$ & & $0.34(0.24-0.46)$ & $0.38(0.27-0.54)$ \\
\hline $25-34$ & $617(18.8)$ & ref. & ref. & & ref. & ref. \\
\hline $35-44$ & $784(26.4)$ & $1.55(1.20-2.00)$ & $1.50(1.16-1.95)$ & & $1.43(1.10-1.86)$ & $1.47(1.10-1.97)$ \\
\hline $45-54$ & $948(34.3)$ & $2.25(1.77-2.87)$ & $2.13(1.67-2.72)$ & & $2.01(1.57-2.58)$ & $1.91(1.44-2.53)$ \\
\hline $55-64$ & $1185(34.8)$ & $2.30(1.82-2.91)$ & $2.13(1.68-2.70)$ & & $2.07(1.62-2.65)$ & $1.68(1.27-2.22)$ \\
\hline \multicolumn{7}{|l|}{ Level of education } \\
\hline Elementary school & $1120(15.2)$ & $0.54(0.44-0.67)$ & $0.60(0.48-0.74)$ & $0.85(0.69-1.06)$ & $0.90(0.72-1.12)$ & $0.92(0.72-1.17)$ \\
\hline High school & $2143(29.9)$ & $1.29(1.10-1.51)$ & $1.39(1.19-1.63)$ & $1.50(1.28-1.76)$ & $1.54(1.30-1.81)$ & $1.69(1.41-2.03)$ \\
\hline University/college & $1291(24.8)$ & ref. & ref. & ref. & ref. & ref. \\
\hline \multicolumn{7}{|l|}{ Country of birth } \\
\hline Sweden & $3853(25.0)$ & ref. & ref. & ref. & ref. & ref. \\
\hline Not Sweden & $701(23.7)$ & $0.93(0.77-1.12)$ & $0.93(0.77-1.13)$ & $0.89(0.73-1.08)$ & $0.99(0.80-1.21)$ & $1.09(0.87-1.37)$ \\
\hline \multicolumn{7}{|l|}{ Type of living area } \\
\hline Big cities & $1458(22.7)$ & ref. & ref. & ref. & ref. & ref. \\
\hline Medium-sized cities & $1815(25.2)$ & $1.15(0.97-1.35)$ & $1.14(0.97-1.34)$ & $1.20(1.01-1.42)$ & $1.14(0.96-1.35)$ & $1.20(0.99-1.46)$ \\
\hline Small cities/villages & $1281(26.7)$ & $1.24(1.04-1.48)$ & $1.25(1.05-1.48)$ & $1.30(1.09-1.56)$ & $1.23(1.02-1.49)$ & $1.28(1.04-1.57)$ \\
\hline \multicolumn{7}{|l|}{ Marital status } \\
\hline Married & $1642(32.1)$ & ref. & ref. & ref. & ref. & ref. \\
\hline Not married & $2912(20.7)$ & $0.55(0.48-0.63)$ & $0.59(0.51-0.67)$ & $0.92(0.79-1.07)$ & $0.92(0.79-1.07)$ & $0.90(0.76-1.07)$ \\
\hline \multicolumn{7}{|c|}{ Partime disability pension } \\
\hline No & $4356(24.3)$ & ref. & ref. & ref. & ref. & ref. \\
\hline Yes & $198(36.9)$ & $1.82(1.35-2.45)$ & $1.65(1.22-2.22)$ & $1.18(0.87-1.60)$ & $1.06(0.78-1.44)$ & $1.03(0.73-1.45)$ \\
\hline
\end{tabular}

Model 1: adjusted for sex

Model 2: adjusted for age

Model 3: adjusted for age, sex, level of education, country of birth, type of living area, marital status, and part-time DP Model 4: adjusted for factors as in model 3 as well as: type of accident, type of injury, and injured body region 


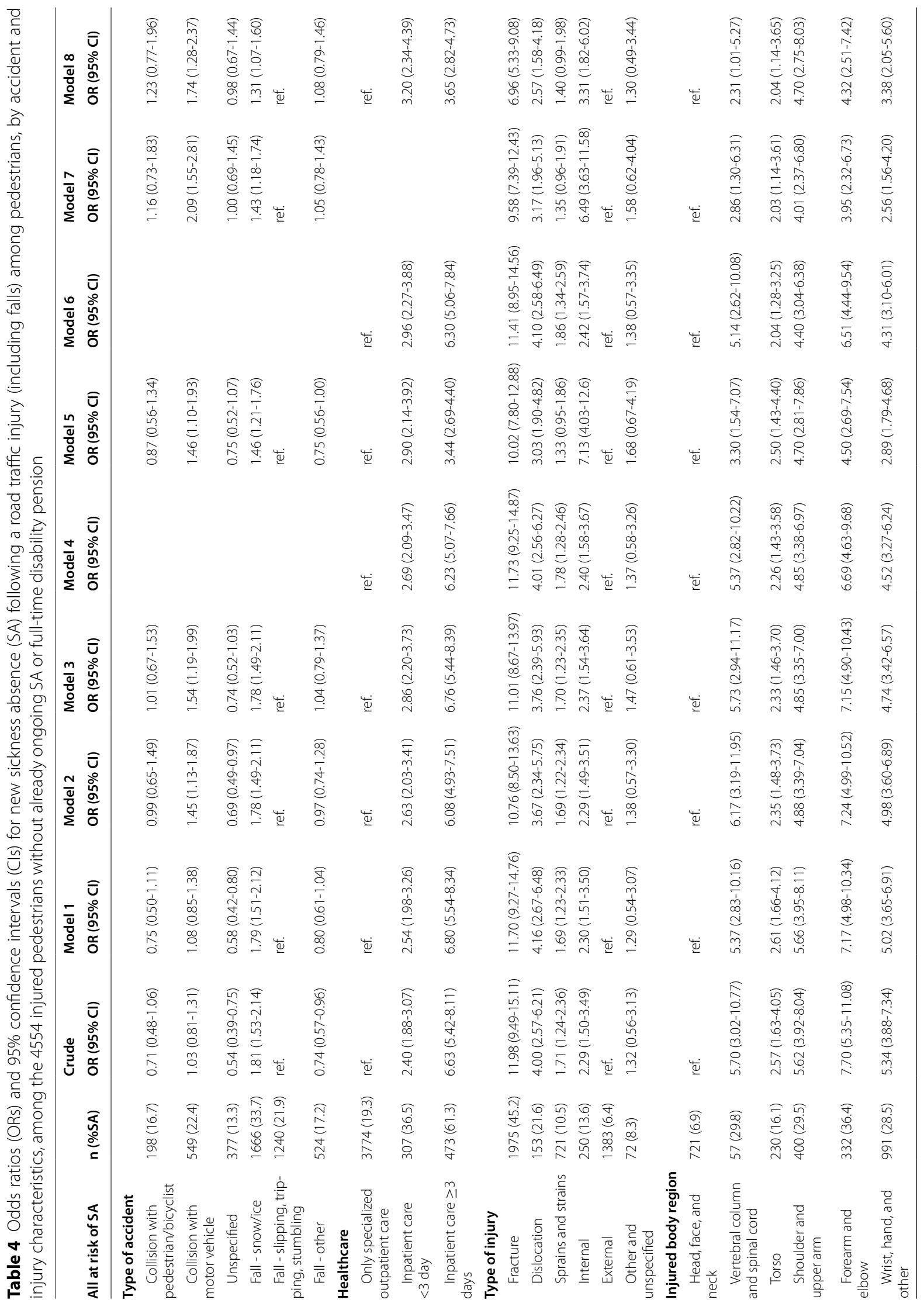




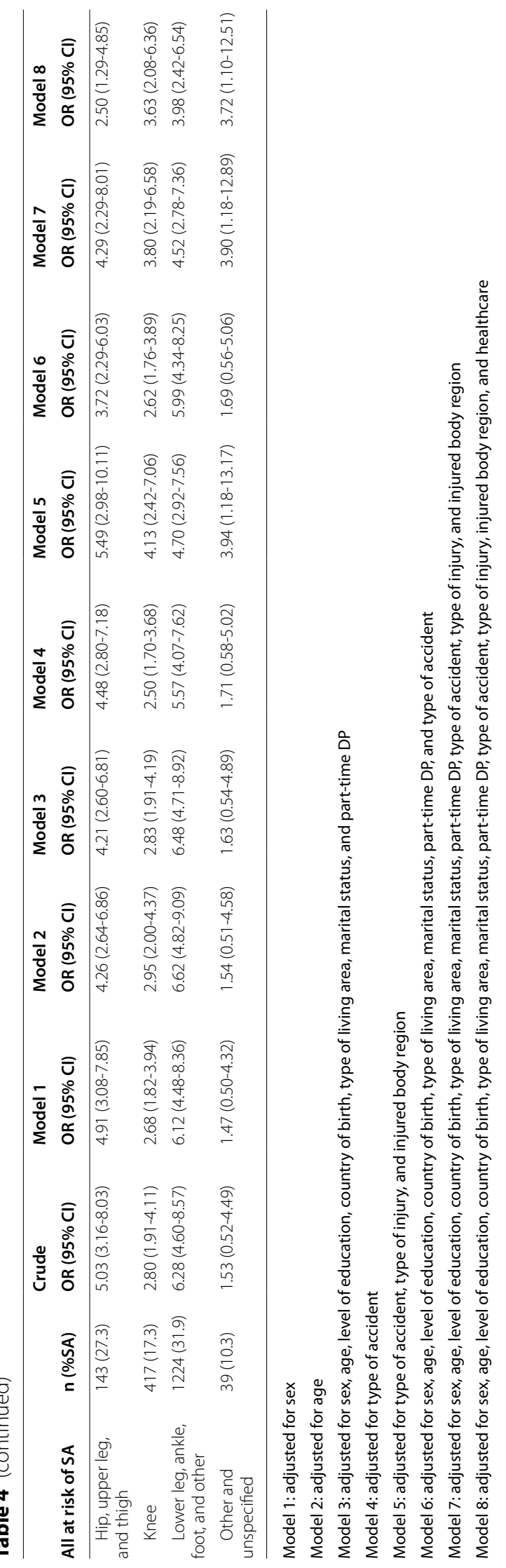


with new SA for a fall related to snow and ice and for a collision with a motor vehicle compared with a fall related to slipping, tripping, and stumbling. This association for a fall related to snow and ice was also seen in the sex-stratified analyses among women, but not among men (Table 5). When examining the type of injury, fractures had a 10-times higher adjusted OR for new SA compared with external injuries. In the sexstratified analyses, both women and men had higher ORs for new SA if having a fracture, a dislocation, or an internal injury. In addition, men had higher ORs for sprains and strains.

Regarding body region, all categories had higher ORs for new SA compared to the category: head, face, and neck. Highest ORs were seen in the three categories: shoulder and upper arm, hip, upper leg and thigh, and lower leg, ankle, foot, and other. Men had the highest ORs for new SA for the two body regions hip, upper leg and thigh, and other and unspecified. Whereas women had high ORs for new SA for the three body regions shoulder and upper arm, forearm and elbow, and lower leg, ankle, foot, and other.

Excluding pedestrians with part-time DP did not change these results (data not shown).

\section{Discussion}

This nationwide register study investigating SA and DP among the 5576 pedestrians of working ages who in 2010 had in- or specialized outpatient healthcare for a new road traffic-related accident (including falls), observed that $20 \%$ had a new SA spell ( $>14$ days) in connection to the accident while $18 \%$ already were on SA or full-time DP. Most (75\%) of the accidents were due to falls and particularly falls related to snow and ice. Falls related to snow and ice had a higher OR for new SA compared to falls related to slipping, tripping and stumbling among women but not among men.

Fractures was the most frequent type of injury among individuals included in the present study and associated with high ORs for new SA compared to external injuries. In general, among pedestrians, fractures followed by external injuries (e.g., contusion, bruise, open wound) have previously been reported to be the most common types of injuries [1, 8]. Head, lower and upper extremities have been reported to be the most frequently injured body regions $[1,8]$. This is in line with our findings where lower leg, ankle, foot, and other (26\%) where the most frequent injured body region, followed by wrist, hand, and other (21\%), and head, face, and neck (16\%). In the present study, all injured body regions had higher ORs for new SA compared to injuries to head, face, and neck. This could be due to the readiness to seek healthcare being higher if your head, face, or neck is injured, while these injuries do not necessarily lead to long ( $>14$ days) SA (e.g. concussion).

There are notably few studies on pedestrian falls [1, 21], However, several studies show that pedestrian falls make up a larger proportion than pedestrians injured in collisions with motor vehicles [21-23]. In this study we found that $75 \%$ of the injuries were due to a fall, $8 \%$ of the injuries occurred in an unspecified accident, and only $16 \%$ of the injuries in the road traffic system were related to an accident with another road user involved. However, in the current definition of traffic accident, only accidents where a vehicle is involved are included [12]. We start all of our journeys as pedestrians, regardless of the other means of transportation taken in the journey. To be able to capture the whole picture of pedestrians' injuries, with a holistic perspective of the entire journey, all pedestrians' accidents are needed to be taken into consideration, not only those involving a vehicle.

It has further been shown that in pedestrian falls, the elderly are over represented (Oxley, 2018). The elderly are more likely to fall and are also more prone to get a fracture when falling [24]. In our study, including adults younger than 65 years, we observed that over half of the injured pedestrian were found in the two oldest age groups (45-54 and 55-64 year of age). These groups also had a higher proportion of new SA in connection to the accident. Equally, higher age is associated with both SA and DP [25]. Even though outdoor falls are associated with an active lifestyle [26] a higher proportion of ongoing SA and full-time DP (18.3\%) was found in the present study compared to two other studies using the same source population of adults of working age in Sweden, studying SA and DP among individuals injured in a car crash (9\% ongoing SA/DP) [16] and bicycle crash (10\% ongoing SA/DP) [17]. This could partly be explained by the slightly older population, compared to the age distribution in the other two studies focused on bicyclists and car occupants. The individuals with ongoing SA or full-time DP are not at risk of new SA and hence were excluded from the analyses. In addition, the analyses were adjusted for age.

Vulnerable road users, such as pedestrians, bicyclists, and motorcyclists sustain severe initial injuries more frequently in the youngest and oldest age groups compared to protected road users who have their highest number of severe injuries in the age-group 25-44 years old [27]. The mean and median number of net days of the new SA spells where higher in the present study compared to above mentioned bicycle crash study [17]. This could be seen in EU where pedestrians represent the road user group with the highest proportion of accidents where the injured is admitted to hospital and also the longest average of hospital stay [8]. Therefore, it should also be of 
Table 5 Odds ratios (ORs) and 95\% confidence intervals (Cls) for new sickness absence (SA) following a road traffic injury (including falls) among pedestrians, by accident and injury characteristics, among the 4554 injured pedestrians without already ongoing SA or full-time disability pension, stratified by sex

\begin{tabular}{|c|c|c|c|c|c|c|c|c|}
\hline \multirow[b]{3}{*}{ All at risk of SA } & \multicolumn{4}{|l|}{ Women } & \multicolumn{4}{|l|}{ Men } \\
\hline & & Crude & Model 2 & Model 7 & & Crude & Model 2 & Model 7 \\
\hline & $n(\% S A)$ & OR $(95 \% \mathrm{Cl})$ & OR $(95 \% \mathrm{Cl})$ & OR $(95 \% \mathrm{Cl})$ & $\mathrm{n}(\% \mathrm{SA})$ & OR $(95 \% \mathrm{Cl})$ & OR $(95 \% \mathrm{Cl})$ & OR $(95 \% \mathrm{Cl})$ \\
\hline \multicolumn{9}{|l|}{ Type of accident } \\
\hline $\begin{array}{l}\text { Collision with } \\
\text { pedestrian/ } \\
\text { bicyclist }\end{array}$ & $93(17.2)$ & $0.60(0.34-1.05)$ & $0.80(0.44-1.43)$ & $1.02(0.52-1.99)$ & $105(16.2)$ & $1.00(0.57-1.77)$ & $1.30(0.72-2.34)$ & $1.33(0.69-2.54)$ \\
\hline $\begin{array}{l}\text { Collision with } \\
\text { motor vehicle }\end{array}$ & $258(24.8)$ & $0.95(0.68-1.31)$ & $1.50(1.06-2.14)$ & $2.60(1.71-3.94)$ & $291(20.3)$ & $1.32(091-1.91)$ & $1.61(1.10-2.36)$ & $1.77(1.13-2.75)$ \\
\hline Unspecified & $164(14.0)$ & $0.47(0.29-0.75)$ & $0.64(0.39-1.04)$ & $0.95(0.55-1.64)$ & $213(12.7)$ & $0.75(0.47-1.20)$ & $0.86(0.53-1.39)$ & $1.10(0.65-1.87)$ \\
\hline Fall - snow/ice & $1068(37.7)$ & $1.74(1.42-2.14)$ & $1.74(1.41-2.16)$ & $1.47(1.15-1.87)$ & $598(26.6)$ & $1.88(1.39-2.53)$ & $1.82(1.34-2.47)$ & $1.37(0.98-1.93)$ \\
\hline $\begin{array}{l}\text { Fall - slipping, } \\
\text { tripping, stum- } \\
\text { bling }\end{array}$ & $739(25.8)$ & ref. & ref. & ref. & $501(16.2)$ & ref. & ref. & ref. \\
\hline Fall - other & $211(17.1)$ & $0.59(0.40-0.88)$ & $0.78(0.52-1.18)$ & $0.76(0.48-1.20)$ & $313(17.3)$ & $1.08(0.74-1.58)$ & $1.32(0.89-1.94)$ & $1.38(0.90-2.12)$ \\
\hline \multicolumn{9}{|l|}{ Healthcare } \\
\hline $\begin{array}{l}\text { Only special- } \\
\text { ized outpatient } \\
\text { care }\end{array}$ & $2113(23.3)$ & ref. & ref. & & $1661(14.2)$ & ref. & ref. & \\
\hline $\begin{array}{l}\text { Inpatient care } \\
<3 \text { days }\end{array}$ & $149(45.6)$ & $2.77(1.97-3.88)$ & $3.54(2.44-5.14)$ & & $158(27.8)$ & $2.33(1.60-3.39)$ & $2.25(1.54-3.31)$ & \\
\hline $\begin{aligned} & \text { Inpatient care } \\
\geq & 3 \text { days }\end{aligned}$ & $271(63.8)$ & $5.82(4.45-7.60)$ & $5.57(4.20-7.39)$ & & $202(57.9)$ & $8.31(6.09-11.35)$ & $7.46(5.42-10.27)$ & \\
\hline \multicolumn{9}{|l|}{ Type of injury } \\
\hline Fracture & $1200(50.5)$ & $11.20(8.39-14.97)$ & $9.99(7.42-13.46)$ & $9.61(6.86-13.46)$ & 775 (36.9) & $12.59(8.49-18.68)$ & $12.17(8.18-18.12)$ & $11.06(7.14-17.13)$ \\
\hline Dislocation & $66(22.7)$ & $3.23(1.71-6.09)$ & $3.19(1.66-6.10)$ & $2.68(1.33-5.39)$ & $87(20.7)$ & $5.62(2.98-10.60)$ & $4.94(2.59-9.42)$ & $4.70(2.32-9.54)$ \\
\hline $\begin{array}{l}\text { Sprains and } \\
\text { strains }\end{array}$ & $392(8.9)$ & $1.08(0.70-1.67)$ & $1.08(0.69-1.68)$ & $0.98(0.61-1.57)$ & $329(12.5)$ & $3.07(1.88-5.01)$ & $3.04(1.85-4.99)$ & $2.10(1.22-3.60)$ \\
\hline Internal & $127(10.2)$ & $1.25(0.67-2.36)$ & $1.50(0.78-2.86)$ & $2.88(1.26-6.58)$ & $123(17.1)$ & $4.43(2.44-8.04)$ & $3.93(2.15-7.18)$ & $16.95(7.14-40.27)$ \\
\hline External & $707(8.3)$ & ref. & ref. & ref. & $676(4.4)$ & ref. & ref. & ref. \\
\hline $\begin{array}{l}\text { Other and } \\
\text { unspecified }\end{array}$ & $41(12.2)$ & $1.53(0.58-4.03)$ & $1.78(0.66-4.82)$ & $1.92(0.64-5.71)$ & $31(3.2)$ & $0.72(0.09-5.44)$ & $0.70(0.09-5.36)$ & $0.86(0.10-7.30)$ \\
\hline \multicolumn{9}{|l|}{ Body region } \\
\hline $\begin{array}{l}\text { Head, face, and } \\
\text { neck }\end{array}$ & $339(8.0)$ & ref. & ref. & ref. & $382(6.0)$ & ref. & ref. & ref. \\
\hline $\begin{array}{l}\text { Vertebral col- } \\
\text { umn and spinal } \\
\text { cord }\end{array}$ & $36(30.6)$ & $5.08(2.26-11.44)$ & $5.56(2.38-12.99)$ & $1.57(0.56-4.39)$ & $21(28.6)$ & $6.24(2.21-17.60)$ & $6.67(2.30-19.38)$ & $5.47(1.54-19.47)$ \\
\hline Torso & $103(14.6)$ & $1.97(1.00-3.86)$ & $1.86(0.93-3.69)$ & $1.15(0.50-2.66)$ & $127(17.3)$ & $3.27(1.75-6.10)$ & $2.91(1.55-5.47)$ & $3.50(1.52-8.05)$ \\
\hline $\begin{array}{l}\text { Shoulder and } \\
\text { upper arm }\end{array}$ & $191(40.3)$ & $7.81(4.79-12.72)$ & $6.31(3.83-10.40)$ & $3.35(1.70-6.60)$ & 209 (19.6) & $3.81(2.21-6.55)$ & $3.52(2.03-6.10)$ & $4.93(2.11-11.50)$ \\
\hline $\begin{array}{l}\text { Forearm and } \\
\text { elbow }\end{array}$ & $219(42.0)$ & $8.37(5.20-13.47)$ & $7.10(4.36-11.56)$ & $2.73(1.40-5.34)$ & $113(25.7)$ & $5.39(2.97-9.79)$ & $6.08(3.30-11.22)$ & $5.74(2.37-13.94)$ \\
\hline $\begin{array}{l}\text { Wrist, hand, } \\
\text { and other }\end{array}$ & $625(34.1)$ & $5.97(3.90-9.15)$ & $4.84(3.13-7.47)$ & $1.60(0.85-3.00)$ & $366(18.9)$ & $3.63(2.21-5.96)$ & $4.20(2.54-6.97)$ & $4.11(1.85-9.15)$ \\
\hline $\begin{array}{l}\text { Hip, upper leg, } \\
\text { and thigh }\end{array}$ & $78(26.9)$ & $4.26(2.25-8.04)$ & $3.52(1.84-6.76)$ & $2.15(0.94-4.90)$ & $65(27.7)$ & $5.98(3.01-11.89)$ & $5.27(2.62-10.61)$ & $11.02(4.16-29.21)$ \\
\hline Knee & $242(16.1)$ & $2.22(1.32-3.74)$ & $2.10(1.23-3.58)$ & $1.98(0.98-4.00)$ & $175(18.9)$ & $3.63(2.06-6.39)$ & $4.32(2.42-7.72)$ & $8.81(3.68-21.13)$ \\
\hline $\begin{array}{l}\text { Lower leg, } \\
\text { ankle, foot, and } \\
\text { other }\end{array}$ & $678(34.8)$ & $6.17(4.04-9.43)$ & $5.94(3.85-9.16)$ & $2.74(147-5.09)$ & $546(28.2)$ & $6.13(3.87-9.72)$ & $7.05(4.40-11.28)$ & $8.44(3.86-18.47)$ \\
\hline $\begin{array}{l}\text { Other and } \\
\text { unspecified }\end{array}$ & $22(9.1)$ & $1.16(0.26-5.21)$ & $1.01(0.22-4.65)$ & $1.44(0.28-7.35)$ & $17(11.8)$ & $2.08(0.45-9.65)$ & $2.51(0.52-12.01)$ & $17.79(3.17-99.80)$ \\
\hline
\end{tabular}


interest to study the SA and DP of pedestrians in a longer perspective as have been done for bicycle crashes [19].

In a country like Sweden, winter lasts for several months and thereby falls related with snow and ice were high in the present study. Specifically, among women falls related to snow and ice had high ORs for new SA compared to fall related to slipping, tripping and stumbling. Snow and ice have been identified as a contributing factor to higher risk of falling $[21,23]$. Days with rain followed by falling temperatures or freezing rain has been found to generate three-fold higher numbers of falls [28]. This implies that local authorities should take a wider responsibility regarding improved maintenance after snow falls. Furthermore, future studies should investigate more in detail how the seasonal variations influence the injury patterns. One explanation for women being at higher risk is that they to a greater extent have osteoporosis and higher propensity to fall [24].

\section{Strengths and limitations}

The use of information from high-quality nationwide registers with total population coverage means that all diagnoses were certified by a physician rather than selfreported, and that all could be included without dropouts [29]. We cannot rule out that sometimes external causes of morbidity and/or secondary diagnoses might not have been recorded. All pedestrian injuries, including those from road traffic accidents due to falls, severe enough to require in- or specialized outpatient healthcare were included, which is often not the case. Another strength is the large number of included individuals allowing for subgroup analyses. The high-quality register-data means that results were not hampered by recall bias.

One limitation is that we did not have data from primary healthcare, however, all the more severe injuries were included. Another limitation is that only one injury diagnosis was taken into consideration; this may have led to under- or overestimation of the impact of different injuries.

This study focuses only on pedestrians of working ages and only to the immediate consequences of the injury, in terms of SA. Long-term consequences, regarding SA and DP, also need to be investigated in future studies. To further elucidate the consequences of pedestrians' injuries, all age groups, need to be taken into consideration. In addition, to also capture the impact of minor accidents, primary healthcare could be considered. Moreover, the impact of intoxication, comorbidities, and use of medications on the associations need to be further evaluated.

In order to provide a complete picture of the occurrence of pedestrian falls within the road traffic system, using register data and the ability to include all injuries is an advantage. The knowledge from this study can be used as basis for more specific recommendations for future policies to contribute to a safer traffic environment for pedestrians which goes beyond for example personal anti-slip devices. While it is not reasonable to believe that it is possible to completely eliminate all accidents, injuries are not unpredictable. Accordingly, evidence-based policies could lead to prevention and less severe injuries when they do incur.

\section{Conclusions}

This nationwide register-based study of pedestrians injured in a road-traffic-related accident including falls, found that $20 \%$ had a new SA spell lasting more than 14 days in connection to the accident and that $18 \%$ already were on SA or full-time DP at the time of the accident. Most of the pedestrians' accidents were falls and in particular falls related to snow and ice. Fractures and internal injuries had the strongest associations with new SA. Women had high ORs for new SA after being involved in a collision with motor vehicle or in a fall related to snow and ice. The later could not be seen among men.

\section{Abbreviations \\ DP: Disability pension; SA: Sickness absence; OR: Odds ratio; Cl: Confidence interval.}

\section{Acknowledgements}

Not applicable

\section{Authors' contributions}

All authors (LK, HS, MK, KA, and EF) contributed to the design of the study. LK performed the data management and the statistical analyses. LK wrote the first draft of the manuscript and revised it with input from all other authors (HS, MK, KA, and EF). All authors (LK, HS, MK, KA, and EF) read and approved the final version of the manuscript.

\section{Funding}

Open access funding provided by Karolinska Institutet. The study was financially supported by Skyltfonden at the Swedish Transport Administration and AFA insurance. The study utilised data from the REWHARD consortium supported by the Swedish Research Council (2017-00624).

\section{Availability of data and materials}

The data cannot be made publicly available, according to privacy regulations. According to the General Data Protection Regulation, the Swedish law SFS 2018:218, the Swedish Data Protection Act, the Swedish Ethical Review Act, and the Public Access to Information and Secrecy Act, data can only be made available, after legal review, for researchers who meet the criteria for access to this type of sensitive and confidential data. Readers may contact professor Kristina Alexanderson (kristina.alexanderson@ki.se) regarding the data.

\section{Declarations}

\section{Ethics approval and consent to participate}

The project was approved by the Regional Ethical Review Board in Stockholm, Sweden.

All methods were carried out in accordance with relevant guidelines and regulations. The Swedish law on Research Ethics states that research use of register data that has been given without consent and contain sensitive information, such as health conditions must get approval from a Regional Ethical 
Review Board as well as from the state authority holding the data which has been done here.

\section{Consent for publication}

Not applicable

\section{Competing interests}

The authors declare that they have no competing interests.

\section{Author details}

${ }^{1}$ Division of Insurance Medicine, Department of Clinical Neuroscience, Karolinska Institutet, SE-171 77 Stockholm, Sweden. ${ }^{2}$ Division of Vehicle Safety, Mechanics and Maritime Sciences, Chalmers University of Technology, Gothenburg, Sweden. ${ }^{3}$ Folksam Research, Folksam Insurance Group, Stockholm, Sweden.

Received: 17 August 2021 Accepted: 23 November 2021

Published online: 14 December 2021

\section{References}

1. Oxley J, O'Hern S, Burtt D, Rossiter B. Falling while walking: a hidden contributor to pedestrian injury. Accid Anal Prev. 2018;114:77-82.

2. STA. In Swedish: Gemensam inriktning för säker gångtrafik 1.0. Borlänge: Swedish Transport Administration; 2017.

3. WHO. Physical activity strategy for the WHO European Region 2016-2025. Copenhagen: World Health Organization; 2016.

4. The 2030 Agenda for sustainable development [https://sustainabledeve lopment.un.org/content/documents/21252030\%20Agenda\%20for\% 20Sustainable\%20Development\%20web.pdf].

5. WHO. Global status report on road safety 2018. Geneva: World Health Organization; 2018

6. Naci H, Chisholm D, Baker TD. Distribution of road traffic deaths by road user group: a global comparison. Inj Prev. 2009;15(1):55-9.

7. Road Safety in the European Union - Trends, statistics and main challenges. Luxemburg; 2018.

8. European Commission. Traffic safety basic facts on pedestrians, European Commission, Directorate General for Transport. 2018.

9. Marmot M, Feeney A, Shipley M, North F, Syme SL. Sickness absence as a measure of health status and functioning: from the UK Whitehall II study. J Epidemiol Community Health. 1995;49(2):124-30.

10. Alexanderson K, Norlund A. Swedish council on technology assessment in health care (SBU). Chapter 1. Aim, background, key concepts, regulations, and current statistics. Scand J Public Health Suppl. 2004;63:12-30.

11. Chakravarthy B, Lotfipour S, Vaca FE. Pedestrian injuries: emergency care considerations. Cal J Emerg Med. 2007;8(1):15-21.

12. Methorst R, Schepers P, Christie N, Dijst M, Risser R, Sauter D, et al. 'Pedestrian falls' as necessary addition to the current definition of traffic crashes for improved public health policies. J Transp Health. 2017;6:10-2.

13. Ludvigsson JF, Otterblad-Olausson P, Pettersson BU, Ekbom A. The Swedish personal identity number: possibilities and pitfalls in healthcare and medical research. Eur J Epidemiol. 2009;24(11):659-67.

14. International Statistical Classification of Diseases and Related Health Problems, Tenth Revision (ICD-10). Geneva: WHO; 1993.

15. Barell V, Aharonson-Daniel L, Fingerhut LA, Mackenzie EJ, Ziv A, Boyko $\checkmark$, et al. An introduction to the Barell body region by nature of injury diagnosis matrix. Inj Prev. 2002;8(2):91-6.

16. Elrud R, Stigson H, Ohlin M, Alexanderson K, Kjeldgård L, Friberg E. Sickness absence among passenger car occupants following a crash. In: IRCOBI Conference Proceedings. 2017: IRC-17-18, s 79-90, ISSN 2235-3151.

17. Kjeldgård L, Ohlin M, Elrud R, Stigson H, Alexanderson K, Friberg E. Bicycle crashes and sickness absence - a population-based Swedish register study of all individuals of working ages. BMC Public Health. 2019;19(1):943.

18. Ohlin M, Kjeldgård L, Elrud R, Stigson H, Alexanderson K, Friberg E. Duration of sickness absence following a bicycle crash, by injury type and injured body region: a nationwide register-based study. J Transp Health. 2018:9:275-81.

19. Kjeldgard L, Stigson H, Alexanderson K, Friberg E. Sequence analysis of sickness absence and disability pension in the year before and the three years following a bicycle crash; a nationwide longitudinal cohort study of 6353 injured individuals. BMC Public Health. 2020;20(1):1710.

20. Social Insurance in Figures 2016. Stockholm, Swedish Social Insurance Agency; 2016.

21. Elvik R, Bjørnskau T. Risk of pedestrian falls in Oslo, Norway: Relation to age, gender and walking surface condition. J Transp Health. 2019;12:359-70.

22. Schepers $P$, den Brinker $B$, Methorst $R$, Helbich M. Pedestrian falls: a review of the literature and future research directions. J Saf Res. 2017:62:227-34.

23. Öberg G. In Swedish: Skadade fotgängare: fokus på drift och underhåll vid analys av sjukvårdsregistrerade skadade i STRADA. (Injured pedestrians : a focus on highway maintenance procedures through analysis of hospital registered injury data from STRADA ): VTI rapport; 2011.

24. Cummings SR, Melton LJ. Epidemiology and outcomes of osteoporotic fractures. Lancet. 2002;359(9319):1761-7.

25. Allebeck P, Mastekaasa A. Swedish Council on Technology Assessment in Health Care (SBU). Chapter 5. Risk factors for sick leave - general studies. Scand J Public Health Suppl. 2004:63:49-108.

26. Kelsey JL, Berry SD, Procter-Gray E, Quach L, Nguyen US, Li W, et al. Indoor and outdoor falls in older adults are different: the maintenance of balance, independent living, intellect, and Zest in the Elderly of Boston Study. J Am Geriatr Soc. 2010;58(11):2135-41.

27. Analysis of road safety trends 2018 - management by objectives for road safety work towards the 2020 interim targets. In., vol. 182 Swedish Transport Administration 2019.

28. Morency P, Voyer C, Burrows S, Goudreau S. Outdoor falls in an urban context: winter weather impacts and geographical variations. Can J Public Health. 2012;103(3):218-22.

29. Ludvigsson JF, Andersson E, Ekbom A, Feychting M, Kim JL, Reuterwall $C$, et al. External review and validation of the Swedish national inpatient register. BMC Public Health. 2011;11:450.

\section{Publisher's Note}

Springer Nature remains neutral with regard to jurisdictional claims in published maps and institutional affiliations.

Ready to submit your research? Choose BMC and benefit from:

- fast, convenient online submission

- thorough peer review by experienced researchers in your field

- rapid publication on acceptance

- support for research data, including large and complex data types

- gold Open Access which fosters wider collaboration and increased citations

- maximum visibility for your research: over 100M website views per year

At BMC, research is always in progress.

Learn more biomedcentral.com/submissions 